\title{
Analysis of Consumer Acceptance Behavior of Future Community APP based on Modified TAM Model
}

\author{
Chenchu Li a , Jing Li ${ }^{b}$, Huirou Xie ${ }^{c}$, Yiyi Lu ${ }^{d}$, Xiaolong Ma ${ }^{e, *}$, Xueer Lou ${ }^{f}$, \\ Yangyang Zhang ${ }^{g}$
}

\author{
School of Business, Huzhou University, Huzhou, Zhejiang 313000, China \\ a1464057797@qq.com, b944278433@qq.com, c1282845241@qq.com,d1242383456@qq.com, \\ e, *329509796@qq.com, ${ }^{\dagger}$ 2587051683@qq.com, g17816782726@163.com
}

\begin{abstract}
Based on the research and development status of future community APP at home and abroad, the consumer acceptance behavior model of future community APP based on modified TAM was proposed. The research data were collected through questionnaire survey, the reliability and validity of the data were analyzed by SPSS software, and the model was tested by AMOS software. Finally, through analyzing the main factors influencing the acceptance behavior of community APP consumers in the future and their influence, effective suggestions and countermeasures are put forward for the development of community APP in the future.
\end{abstract}

Keywords: Future Community APP Use; TAM Model; Consumer Acceptance Behavior.

\section{Introduction}

With the continuous development of Internet technology and the in-depth construction of 5G network, communities, as the basic unit of cities, are increasingly eager to become smart, Low-carbon, shared and full of humanistic care [1]."Smart" communities are characterized by three aspects: first, information resource sharing, second, the needs of community residents as the starting point, and third, urban management and community informatization [2]. At present, Zhejiang takes the lead in pressing the start button for the construction of "future community". In order to solve the problems existing in traditional communities, create a more comfortable living environment, and strive to build the future community into a people's community with the fundamental purpose of meeting people's yearning for a better life.

Although China's community APP construction is becoming more and more perfect, but the traditional community APP still cannot solve some problems in the community:(1) There are many loopholes in prevention and control in traditional communities during the epidemic;(2) The relationship between community and neighborhood is increasingly weak [3]; (3) The phenomenon of idle and waste public space in traditional communities is serious [4]; (4) Community health service centers are empty, and all kinds of resources are wasted to some extent. As sharing economy is rapidly integrated into our lives, it is the development direction of community apps in the future. It is in line with the new development concept of "innovation, coordination, green, open and sharing". By using the intelligent development of sharing economy, it can effectively improve the recycling efficiency of social resources and steadily build a new carrier and platform for neighborhood communication. At the same time, THE INITIAL use of 5G network, with the help of 5G network to develop the sharing economy in the community, in line with the requirements of the future community, is also an important thrust for China to achieve economic transformation and upgrading. Sharing economy and $5 \mathrm{G}$ technology can not only effectively promote the comprehensive upgrade and improvement of community APP, but also drive the community to develop towards digital, ecological and humanistic direction with the help of APP development. 


\section{Literature Review}

Based on CNKI database, this paper searches with "future community" or "Future Community APP" as the main title. Through reading the research of domestic scholars on this issue, the theoretical research results are roughly classified into the following three categories:

\subsection{Research on Low-carbon Energy Communities}

As the greenhouse effect becomes more and more serious, the ecological environment of the earth is facing a great threat. Low-carbon travel, Low-carbon production and so on are often mentioned, followed by the construction of Low-carbon city, Low-carbon community calls are also increasingly high. Zhang Xi, Lin Junguang, Ye Lei, Yu Libin [5] et al., based on the assumption of the Low-carbon energy scenario in the future community, proposed that the Low-carbon scenario in the future community mainly involves the digital comprehensive energy supply system, classified and graded resource recycling system, and comprehensive energy intelligent service platform. The basic equipment configuration and functions of future community Low-carbon energy scenarios (including future community + power plant scenario, future community + natural gas scenario and future community user scenario) are envisaged. And Dong Kai et al believe that low carbon building, low carbon technology and low carbon culture, three blocks of content is the core component of low carbon community, in the process of low carbon construction is the need to improve the community's awareness of energy conservation and emission reduction through community planning, architectural design, district renovation and other means, and finally form a sustainable development of low carbon community.

\subsection{Research on Home Care Communities}

With the rapid development of society and economy, how to perfectly solve the problem of population aging has become a contemporary problem that must be thought and solved. Recently, the emergence of community home care service model not only provides a new way to solve the problem, but also provides a new idea for the development of China's pension industry. After all, the construction of elderly care communities is still a new thing. As the scholar Li Yange [6] proposed, the purchase of home care services by the Chinese government is still in the exploratory stage, and only a few developed cities have experimented with it, mainly including formal purchase, entrusting purchase and contractual purchase.

\subsection{Research on the Future Community of Lexian}

In the study of Zhou Yong [7] et al., Lixian Future Community builds the "three Gracious" future community by integrating the $4+X "$ innovation scene system, focusing on the three-dimensional value coordinates of humanism, ecology and digitalization, taking the development of high-quality life as the main axis, and paying attention to the design of the four main scenes featuring the future neighborhood, education, health and governance. To provide residents with a humanistic community with temperature in the neighborhood, a natural community with toughness in the environment, and an orderly community with precision in management.

Under the yearning for a better life, the future community came into being. Note JiaoRen this future community and greening, digital, through the neighborhood, education, health, business, construction, transportation, energy, real estate and construction management and so on nine big scene, will otherwise idle space, skills, such as medical resource utilization, promote the construction of future community service constantly optimized, community idle resources rational allocation, We are committed to realizing the vision of a better life for all residents. To realize the pattern of pluralistic co-governance, to maximize the satisfaction of the interests of autonomous subjects, to realize the real community sharing. 


\section{Model Construction}

\subsection{Based on TAM1.1. based on TAM Model Assumptions}

The technology acceptance model holds that the system use is determined by the behavior intention, while the behavior intention is jointly determined by the desired attitude and perceived usefulness, the desired attitude is jointly determined by the perceived usefulness and ease of use, the perceived usefulness is jointly determined by the perceived ease of use and external variables, and the perceived ease of use is determined by external variables.For example, whether consumers accept the future community app is based on many factors such as app usefulness, ease of use, security, trustworthiness, behavior control and service quality. Therefore, this paper puts forward the following assumptions:

H1a: the future community app will help to understand community information;

H1b: Community app will help provide community services in the future;

H1c: the future community app will help to improve the quality of community life;

$\mathrm{H} 2 \mathrm{a}$ : the future community app is easy to operate;

$\mathrm{H} 2 \mathrm{~b}$ : you can quickly find the required services in the future community app;

$\mathrm{H} 2 \mathrm{c}$ : in the future, community app can quickly respond to the service needs of residents;

H3a: the information and services provided by the future community app are trustworthy;

$\mathrm{H} 3 \mathrm{~b}$ : the future community app services can meet the needs of residents;

$\mathrm{H} 3 \mathrm{c}$ : in the future, community app can realize intelligent community service;

$\mathrm{H} 4 \mathrm{a}$ : the future community app system is safe and reliable;

$\mathrm{H} 4 \mathrm{~b}$ : in the future, community app will not disclose residents' private information;

H4c: the future community app network environment is safe;

H5a: residents can use the future community app every day;

$\mathrm{H} 5 \mathrm{~b}$ : residents think they can make good use of the future community app

H5c: residents believe that the future community app is the right choice to improve the quality of community life;

H6a: there will be a wide range of community app services in the future;

H6b: flexible community app service in the future;

H6c: high efficiency of community app service in the future;

$\mathrm{H} 7 \mathrm{a}$ : residents are satisfied with the app page design of the future community;

H7b: residents are satisfied with the future community app service content;

H7c: residents are satisfied with the future community app use experience;

\subsection{Based on TAM Construction of Model}

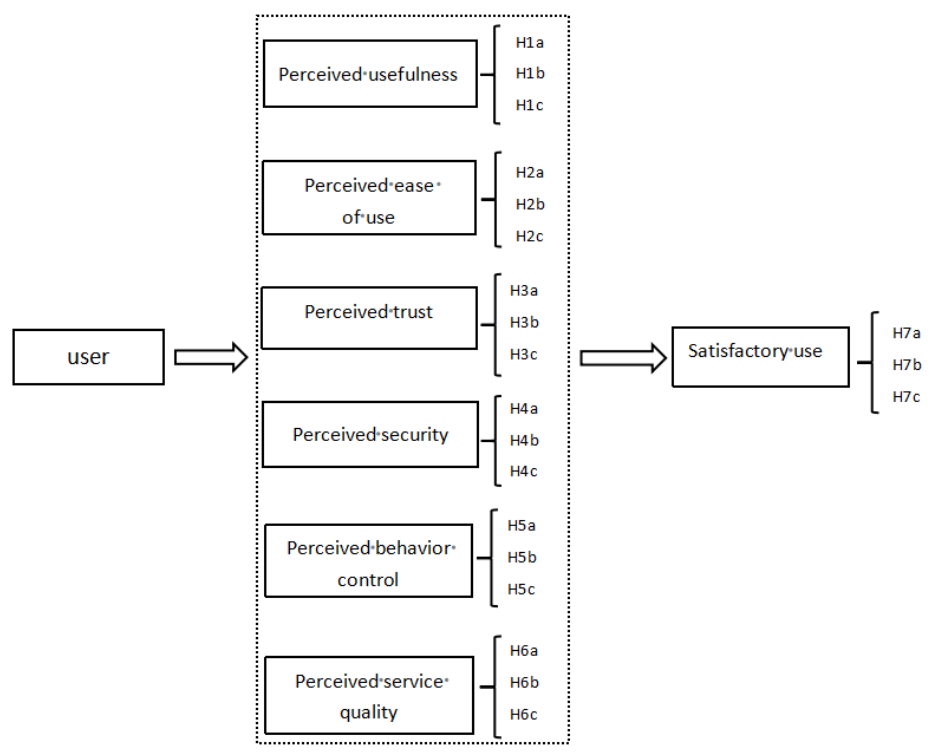

Figure 1. Research Model 
The research model is shown in the Figure 1.

\section{Data Analysis}

\subsection{The Questionnaire Distributed}

\section{Questionnaire Content design}

This study adopts the method of questionnaire survey to investigate the use of community apps by community residents and consumers.Due to the fact that some of the respondents have never used community apps, relevant questions are deliberately set in the questionnaire design to ensure the authenticity and validity of the data. When the first draft of the questionnaire was completed, a smallscale preliminary survey was conducted among friends, classmates and family members who had used the community APP.According to the results and feedback of the preliminary survey, the ambiguity and ambiguity in the initial questionnaire were modified to ensure the accuracy and rationality of the wording of the questionnaire, and its validity and reliability were analyzed.Finally, the revised questionnaire is mainly divided into two parts:The first part is about the basic information of the respondents, including their gender, age, educational background and experience of using community apps. The second part is about the specific content of influencing factors of consumer acceptance behavior of community APP, The questionnaire was set mainly from six dimensions of perceived usefulness, perceived ease of use, perceived trust, perceived security, perceived behavioral control and perceived service quality.For these six dimensions, a total of 23 question options were set in the questionnaire, and each question option used the Five-point Likert method. "Fully agree", "agree", "uncertain", "disagree" and "completely disagree" were used to indicate the respondents' degree of agreement to the listed questions.

2.Respondents and locations

Our team adopts the method of random sampling for questionnaire survey.The survey was conducted from May to December 2020 and mainly selected communities in Hangzhou, including Beijingyuan District, Hanggang Living Area, Huafeng Community, etc, The objects of distribution and data collection are consumer groups and community residents aged 18 to 60 who use traditional community apps.As the future community construction is still in the preliminary stage, the survey site is selected in the pilot area of the future community, and the survey method to some extent enhances the standard and standardization of the subject of the questionnaire.

3.Questionnaire distribution and collection

The data collection of this questionnaire survey is mainly through online and offline methods. The online questionnaires are mainly distributed on the questionnaire star network platform, supplemented by QQ, wechat, weibo and other forms. Offline mainly in Hangzhou.A total of 1126 samples were collected. A total of 600 questionnaire samples were distributed offline, and 481 were actually recovered with a recovery rate of $80.17 \%$, which was in line with the normal recovery rate;A total of 645 valid responses were obtained from the online survey.

\subsection{Descriptive Statistics}

In the questionnaire, the first part contains four variables: gender, age, educational background and experience of using future community APP products. Among them, the gender variable is mainly male and female.In view of the fact that most users of community apps are adults, the survey objects in this study are divided into five groups: under 18 years old and over 18 years old.Educational background is divided into four categories: junior high school and below, senior high school and technical secondary school. The experience variables of using the future Community APP are divided into three categories: frequent, occasional, and none.In this study, SPSS 22 software was used to conduct descriptive statistical analysis of 645 valid questionnaires, as shown in Table 1 below: 
Table 1. Statistical characteristics of samples

\begin{tabular}{|c|c|c|c|}
\hline variable & category & frequency & percentage $(\%)$ \\
\hline \multirow{2}{*}{ gender } & male & 363 & 56.3 \\
\hline & female & 282 & 43.7 \\
\hline \multirow{5}{*}{ age } & Under the age of 18 & 17 & 2.6 \\
\hline & 18 to 35 years old & 371 & 57.5 \\
\hline & 36 to 45 years old & 184 & 28.5 \\
\hline & 46 to 55 years old & 55 & 8.5 \\
\hline & Over 55 & 18 & 2.9 \\
\hline \multirow{4}{*}{ Record of formal schooling } & Junior High and below & 54 & 8.4 \\
\hline & High school and technical secondary school & 167 & 25.9 \\
\hline & Junior College and Undergraduate & 356 & 55.2 \\
\hline & Graduate student or above & 68 & 10.5 \\
\hline \multirow{3}{*}{$\begin{array}{l}\text { Experience with future Community APP } \\
\text { products }\end{array}$} & frequent & 208 & 32.3 \\
\hline & occasional & 311 & 48.2 \\
\hline & none & 126 & 19.5 \\
\hline
\end{tabular}

According to sample characteristics Table 1, there are 363 males, accounting for $56.3 \%$, and 282 females, accounting for $43.7 \%$. in terms of the age of the respondents, 17 were under the age of 18 , accounting for $2.6 \%$; 371 people aged between 18 and 35 were surveyed, accounting for $57.5 \%$; The number of people aged 36 to 45 was 184, accounting for $28.5 \%$; 55 people aged between 46 and 55 were surveyed, accounting for $8.5 \%$. The number of respondents over 55 was 18 , accounting for $2.9 \%$.In terms of education, 356 people have bachelor's degree, accounting for $55.2 \%$; 68 people have master's degree or above, accounting for $10.5 \%$ of the total sample, high school or technical secondary school account for $25.9 \%$, and middle school and below account for $8.4 \%$. It can be seen that people with junior college degree or above account for the majority of the total sample, accounting for about $80 \%$.In general, people who use community apps are mainly middle-aged and young people aged 1845 , and most of them have college degrees or above. Therefore, in promoting future community apps, the government can mainly target at this group of people, design community apps that are more suitable for their needs, and improve consumers' acceptance of behavior.

\subsection{Reliability Analysis}

Table 2. Reliability analysis table of the population scale

\begin{tabular}{|c|c|}
\hline Cornbach's a & The number of projects \\
\hline 0.979 & 18 \\
\hline
\end{tabular}

Table 3. Reliability analysis table of each variable

\begin{tabular}{|c|c|c|}
\hline Variable & Cornbach's a & The number of projects \\
\hline Perceived usefulness & 0.905 & 3 \\
\hline Perceived ease of use & 0.973 & 3 \\
\hline Sense of trust & 0.951 & 3 \\
\hline Perception of security & 0.986 & 3 \\
\hline Perceptual behavior control & 0.983 & 3 \\
\hline Perceived quality of service & 0.998 & 3 \\
\hline
\end{tabular}


In this study, Alpha method was used to detect whether there was a high internal consistency among items. Generally speaking, the reliability coefficient greater than 0.9 indicates that the reliability is very good; the coefficient between 0.8 and 0.9 indicates that the reliability is good; the coefficient between 0.7 and 0.8 indicates that some items need to be modified; and the coefficient below 0.7 indicates that some items need to be discarded. Table 2 and Table 3 show that the overall Alpha value of the questionnaire is 0.979 , and the Alpha value of each variable is greater than 0.9, indicating that the questionnaire has good reliability.

\subsection{Validity Test}

The scale in the questionnaire must be reliable and energy efficient at the same time, so that the data investigated by the scale can be of analytical value.In order to ensure the accuracy and scientificity of the results of the questionnaire survey and make the questionnaire data more able to reflect the problems to be studied, the questionnaire questions should be screened and adjusted, and the validity test should be carried out after the reliability analysis.Validity refers to the degree to which the measurement tool or means can accurately measure the things to be measured, that is, whether the measurement results reflect the effectiveness of the characteristics of the things to be measured. Factor analysis method is usually used to measure the validity of the questionnaire. before factor analysis, KMO and Bartlett tests should be performed on the questionnaire to measure whether the correlation between the questionnaire items meets the criteria for factor analysis verification. $\mathrm{KMO}$ is kaiser-Meyer-Olkin's measurement sampling appropriateness, and its metrics are as follows:

Table 4. KMO metrics

\begin{tabular}{|c|c|c|c|c|c|c|}
\hline KMO & $>0.9$ & $0.9-0.8$ & $0.8-0.7$ & $0.7-0.6$ & $0.6-0.5$ & $<0.5$ \\
\hline Suitability factor analysis & very fit & quite fit & fit & not quite fit & barely fit & not fit \\
\hline
\end{tabular}

In this study, SPSS software was used to conduct KMO and Bartlett tests, and the results were shown in the Table 5:

Table 5. KMO and Bartlett tests

\begin{tabular}{|c|c|c|}
\hline KMO Measure of Sampling Adequacy & & 0.932 \\
\hline Bartlett Test of Sphericity & Approx.Chi-Square & 2637.551 \\
\hline & df & 153 \\
\hline Sig & .000 \\
\hline
\end{tabular}

As shown in the Table 5, the KMO value is 0.932 , and the Sig value tends to 0 , indicating that it is suitable for factor analysis. SPSS software was used for factor analysis. After rotation, the factor load values of each variable were shown in the following Table 6.

It can be seen from the Table 6 that in the factor load matrix after rotation of each variable, the load coefficients of measurement items contained in each variable are all above 0.5 , indicating that the questionnaire data have certain validity.

\subsection{Correlation Analysis}

Correlation analysis is a quantitative analysis method to analyze the correlation between objective things. Many things or phenomena are always related to each other, and can be reflected through a certain number of relationships. The research content of this paper is the influencing factors of consumer acceptance behavior of community APP in the future, which is applicable to linear correlation. Correlation coefficient $\mathrm{R}$ is used to represent the relation degree between the two variables, the correlation coefficient of the scale is between 1 and +1 , if $|R|$ infinite close to 0 , showed no linear correlation between two variables. If the $|r|$ infinitely close to 1 , the said two variables linear correlation completely. in this paper, Pearson correlation coefficient was used to 
analyze the correlation between perceived usefulness, perceived ease of use, perceived trust, perceived security, perceived behavioral control, perceived service quality and consumers' satisfaction with future community apps. In this paper, SPSS software was used for correlation analysis, and the correlation coefficients between variables were finally obtained as shown in the Table 7:

Table 6. Rotation component matrix

\begin{tabular}{|c|c|c|}
\hline Variable & Measuring project & Load factor \\
\hline \multirow{3}{*}{ Perceived usefulness } & PU1 & 0.872 \\
\hline & PU2 & 0.882 \\
\hline & PU3 & 0.895 \\
\hline \multirow{3}{*}{ Perceived ease of use } & PEOU1 & 0.656 \\
\hline & PEOU2 & 0.658 \\
\hline & PEOU3 & 0.665 \\
\hline \multirow{3}{*}{ Sense of trust } & PT1 & 0.716 \\
\hline & PT2 & 0.666 \\
\hline & PT3 & 0.691 \\
\hline \multirow{3}{*}{ Perception of security } & PS1 & 0.823 \\
\hline & PS2 & 0.827 \\
\hline & PS3 & 0.840 \\
\hline \multirow{3}{*}{ Perceptual behavior control } & $\mathrm{PBC} 1$ & 0.704 \\
\hline & $\mathrm{PBC} 2$ & 0.601 \\
\hline & PBC3 & 0.528 \\
\hline \multirow{3}{*}{ Perceived quality of service } & PSQ1 & 0.678 \\
\hline & PSQ2 & 0.637 \\
\hline & PSQ3 & 0.663 \\
\hline
\end{tabular}

Table 7. Correlation between variables and the satisfaction of using future community APP

\begin{tabular}{|c|c|c|c|}
\hline & Pearson correlation & Significance (bilateral) & $\mathrm{N}$ \\
\hline Perceived usefulness & $0.736^{* *}$ & 0.000 & 104 \\
\hline Perceived ease of use & $0.829^{* *}$ & 0.000 & 104 \\
\hline Sense of trust & $0.848^{* *}$ & 0.000 & 104 \\
\hline Perception of security & $0.770^{* *}$ & 0.000 & 104 \\
\hline Perceptual behavior control & $0.740^{* *}$ & 0.000 & 104 \\
\hline Perceived quality of service & $0.945^{* *}$ & 0.000 & 104 \\
\hline
\end{tabular}

**, at level 0.01 (double tail), the correlation was significant.

It can be seen from the Table that variables such as perceived usefulness, perceived ease of use, perceived trust, perceived security, perceived behavioral control and perceived service quality are significantly and positively correlated at 0.01 level, and the coefficients are $0.736,0.829,0.848,0.770$, 0.740 and 0.945 , respectively. In conclusion, the stronger the perceived usefulness, perceived ease of use, perceived trust, perceived security, perceived behavioral control and perceived service quality of future community apps are, the stronger the satisfaction of using future community apps will be. 


\subsection{Structural Equation}

Structural equation modeling is a method of establishing, estimating and testing causality model, also known as covariance structural analysis. The model contains both observable explicit variables and potential variables that cannot be observed directly.Structural equation model can replace multiple regression, path analysis, factor analysis, covariance analysis and other methods to clearly analyze the role of single indicators on the whole and the relationship between single indicators. Chi square ( $\mathrm{x}$ ) is generally used in the research process ${ }^{2}$ ), Represents whether the observation matrix and the theoretical estimation matrix are compatible, so the smaller the value, the better. Generally, the ratio of chi square to degrees of freedom $\left(\mathrm{x}^{2} / \mathrm{DF}\right)$ judge whether to accept the model, and the value is between 2-5. This paper uses chi square index to analyze the interaction of perceived usefulness, perceived ease of use, perceived trust, perceived security, perceived behavior control, perceived service quality and consumer acceptance behavior. Amos21.0 software is used for data processing, and the research results are shown in the Table below.

Table 8. Fitting index

\begin{tabular}{|l|c|c|}
\hline \multicolumn{2}{|c|}{ Index name } & evaluation criterion \\
\hline \multirow{2}{*}{ Absolute fitting index } & $\mathrm{x}^{2}$ (Chi Square) & The smaller the better \\
\cline { 2 - 3 } & GFI & 0.8937 \\
\hline
\end{tabular}

It can be seen from the above Table that the chi square coefficient is 0.8937 and the value is small. It can be seen that the theoretical model has a high degree of adaptation to the data, which can be used as a reference for model adaptation.

\section{Research Conclusion}

Based on the modified TAM model and community literature at home and abroad, this paper explores the characteristics of consumer acceptance behavior of community APP in the future. The main conclusions are as follows:

(1) The usefulness, ease of use, security, trustworthiness, behavior control and service quality of the APP have a high degree of internal consistency.

(2) There is a positive correlation between perceived usefulness, perceived ease of use, perceived trust, perceived safety, perceived behavioral control and perceived service quality, indicating that from the perspective of consumers' satisfaction with future community APP, residents have a high degree of satisfaction with the page design, service content and use experience of future community APP.

\section{Management and Enlightenment}

This paper has certain reference significance for the satisfaction of community APP consumers' acceptance behavior in the future. On the basis of promoting the service quality of community, meeting the service needs of APP consumers, and enhancing the safety and efficiency of the use of community APP, it will further promote the sustainable and healthy development of community APP in the future. Based on the above analysis, this paper puts forward the following suggestions:

(1) to strengthen the construction of the future community APP system, using advanced technology to provide consumers with efficient and convenient, security and stability of the system environment, in order to improve the accuracy of the information, timeliness and service quality, make full use of idle resources, community relies on $5 \mathrm{~g}$ Internet technology, VR video broadcast, make future community APP consumer experience more rich, convenient service.

(2) Maintain the relationship with old customers by means of discounts and gifts, improve the satisfaction of old customers, and achieve the purpose of word-of-mouth promotion for old customers, so as to develop new customers. 
(3) Pay attention to the innovation and beauty of APP advertisements, pay attention to the construction of platform reputation, and create a good corporate image to win the trust of consumers and enhance the satisfaction of APP consumers in the community in the future.

\section{Acknowledgments}

This work is supported by National College Student Innovation Training Program. (Project number: 202010347052X, project name:(Future residence -- future community service platform based on sharing economy), the Zhejiang University Student' science and technology innovation project. (Project number: 2020R442030, project name: Huzhou xinlu Mulberry-based fish pond Technology Development Co., LTD).

\section{References}

[1] Editorial Department of The Journal. Promote the construction of new community and explore the future human settlement system. Construction Science and Technology,2020(23):1.

[2] Zhu Jiaxin. Research on the development status and Future trend of smart community at home and abroad [D]. Anhui University of Science and Technology, 2019.

[3] Liu Na. Analysis of influencing Factors of Neighborhood Relationship in Urban Community [D]. Shanghai Jiaotong University,2019.

[4] CAO Fei. Research on new rural Community Public Space Planning Model [D]. Yunnan University,2015.

[5] Zhang Xi. Lin Junguang. Ye Lei. Yu Libin. Future Scenarios of Low-carbon energy in community [J]. Vol. 39 No.12 Dec.2019.

[6] Li Yange. Government purchase of home care services: Long-term mechanism, dilemma and THREEDIMENSIONAL Approach [J]. Journal of Suihua University. 05 issue 2019.

[7] Zhou Yong. Research on Characteristic Scene Design of Future Community -- Taking Lixian Future Community as an example [J]. Landscape Architecture Design and Research Institute, China Academy of Art, Hangzhou 310012, China. 